\title{
Modelling Local Gravity Anomalies from Processed Observed Gravity Measurements for Geodetic Applications
}

Eteje, S. O. , Oduyebo, O. F. and Oluyori, P. D.

Nnamdi Azikiwe University, Awka, Anambra State, Nigeria

Corresponding Author*: eteje.sylvester@yahoo.com

\section{ABSTRACT}

As the application of gravity data in applied sciences such as geodesy, geodynamics, astronomy, physics and geophysics for earth shape determination, geoid model determination, computation of terrestrial mass displacement, orbit computation of natural and artificial celestial bodies, realization of force standards and derived quantities and density distribution in the different layers in the upper crust and having considered the cost of direct gravity survey, the study presents modelling local gravity anomalies from processed observed gravity measurements for geodetic application in Benin City. A total of 22 points were used. The points were respectively observed with CHC900 dual frequency GNSS receivers and SCINTREX CG-5 Autograv to obtain their coordinates and absolute gravity values. The theoretical gravity values of the points were computed on the Clarke 1880 ellipsoid to obtain their local gravity anomalies. The free air and the Bouguer corrections were applied to the computed gravity anomalies to obtain the free air and the Bouguer gravity anomalies of the points. Least squares adjustment technique was applied to obtain the model variables coefficient/parameters, as well as to fit the fifth-degree polynomial interpolation surface to the computed free air and the Bouguer gravity anomalies. Kriging method was applied using Surfer 12 software to plot the computed and the models' free air and Bouguer gravity anomalies. Microsoft Excel programs were developed for the application of the models in the study area. The Root Mean Square Errors (RMSEs) and the standard errors of the two models were computed to obtain the dependability, as well as reliability of the models. It is recommended that whenever either free air or Bouguer gravity anomalies of points within Benin City are to be obtained for application in applied sciences, the determined models should be applied.

Keywords: Modelling, Free Air, Bouguer, Gravity, Anomalies, Geodetic Application, Benin City

\section{INTRODUCTION}

The application of local gravity data set in geodesy, geology, geophysics among others has led to different ways of sourcing the data. Locally, the data are obtained by carrying out gravity measurement with a gravity meter usually known as gravimeter. Globally, these data are obtained from satellite observation. To obtain these data locally using the gravimeter requires points of interest to be selected, selected points are monumented, carrying out DGPS/GNSS observation, carrying out gravity observation, processing the GNSS and the gravity observations. The GNSS observations are processed in the local datum, as well as the local ellipsoid adopted for geodetic computation in the area of study. Therefore, the coordinates of the selected points are obtained in the local datum. The local geodetic coordinates of the points are used for the computation of the theoretical, as well as the latitude gravity of the points. For the standard gravity to be 
local, the computation has to be carried out on the local datum, as well as the local ellipsoid. The processing of gravimeter reading requires drift correction, atmospheric correction, free air correction, Bouguer correction and terrain correction. The drift is obtained either by reoccupying previously observed points or by closing the loop observations at the reference station. The computation of the gravity anomalies of the selected points which is the difference between the absolute gravity values reduced to the geoid and the latitude gravity computed on the local ellipsoid requires two basic corrections such as free air and Bouguer corrections. Gravity survey is very expensive. It requires the cost of instruments (GNSS receivers and gravimeter) hiring, cost of observation (GNSS and gravity observations), cost of labour and cost of data processing. According to Mariita (2009), gravity surveying is a labour-intensive procedure requiring significant care by the instrument observer. Gravity instruments require careful levelling before a reading is taken. In most cases, gravity observation exercise is normally carried out either by the State or Federal Government agencies. Usually, if the local gravity data acquisition exercise is to be undertaken by individuals, the number of observation points/stations is very small because of the cost of the survey. With the few points whose gravity anomalies have been determined, the gravity anomalies of new points can be modelled by fitting an interpolation surface to the points of known gravity anomalies.

The modelling of gravity anomalies from a set of processed gravity measurements requires the application of Geostatistical interpolation method. It involves the use of Kriging method. The method represents a true Geostatistical approach to interpolating a trend surface of an area. The method involves a two-stage process where the surface representing the drift of the data is built in the first stage and the residuals for this surface are calculated in the second stage. Applying the Kriging method, the user can set the polynomial expression used to represent the drift surface.

Gravity surveys have been carried by different researchers in various parts of the world at different accuracy, as well as reliability. Dawod (1998) established a national gravity standardization network for Egypt and respectively got RMSEs of $28.55 \mathrm{mGal}$ and $28.38 \mathrm{mGal}$ for free air and Bouguer anomalies. Cattin et al. (2015) carried out a gravity survey for the development of MATLAB software and got uncertainties of $2.6 \mathrm{mGal}$ and $2.8 \mathrm{mGal}$. Also, Yilmaz and Kozlu (2018) compared three Global gravity models anomalies with observed values in western Anatolian parts of Turkey and got RMSEs of $15.42 \mathrm{mGal}$ to $16.02 \mathrm{mGal}$ for free air anomalies and $8.12 \mathrm{mGal}$ to $110.17 \mathrm{mGal}$ for Bouguer anomalies and standard deviation of $13.45 \mathrm{mGal}$ to $13.88 \mathrm{mGal}$ for free anomalies and $8.05 \mathrm{mGal}$ to $9.75 \mathrm{mGal}$ for Bouguer anomalies.

Gravity data set is required for application in geodesy, geodynamics, astronomy, physics and geophysics. Mickus (2004) also gave the application of gravity data set in environmental and engineering as follow: (1) detection of subsurface voids including caves, adits, mine shafts, (2) determining the amount of subsidence in surface collapse features over time (3) determination of soil and glacier sediment thickness (bedrock topography), (4) location of buried sediment valleys, (5) determination of groundwater volume and changes in water table levels over time in alluvial basins, (6) mapping the volume, lateral and vertical extent of landfills, (7) mapping steeply dipping contacts including faults and (8) determining the location of unexploded ordinances. According to Oluyori and Eteje (2019), since not all points can be observed or visited physically on the ground, the need for prediction/interpolation to obtain acceptable data/information is very important for decision making and analysis. In order for scientists and engineers in the above mentioned fields to carry out 
their studies and solve problems relating to the environment and the earth itself which require the application of gravity data in Benin City, this study has determined the absolute gravity values of some selected points, computed their local gravity anomalies and fitted an interpolation surface to enable the gravity anomaly of any point of known coordinates to be determined by interpolation/prediction within Benin City. Consequently, the study presents modelling local gravity anomalies from processed observed gravity measurements for geodetic applications.

\subsection{The Study Area}

The study area is Benin City. It is the capital of Edo State in southern Nigeria. It is located in the southern part of the state. It consists of three Local Government Areas, Oredo LGA, Ikpoba Okha LGA and Egor LGA. Benin City is bounded at the north by Ovia North and Uhunmwode Local Government Areas, the west by Orhionmwon LGA, the east by Ovia South West LGA and the south by Delta State. It lies between latitudes $06^{\circ} 01^{\prime} 54^{\prime \prime} \mathrm{N}$ and $06^{\circ} 25^{\prime} 35^{\prime \prime} \mathrm{N}$ and longitudes $05^{\circ} 26^{\prime} 23^{\prime \prime} \mathrm{E}$ and $05^{\circ} 50^{\prime} 05^{\prime \prime} \mathrm{E}$. It occupies an area of about 1,204 square kilometres with a population of about $1,749,316$ according to 2019 projection. Figures 1a and 1b show the map of the study area. The study area topography is relatively flat.

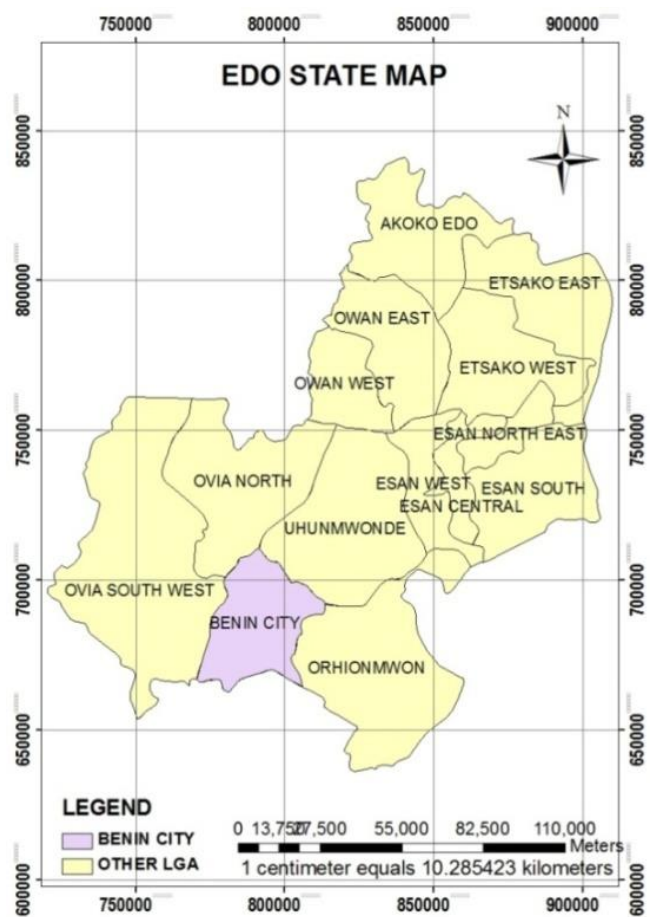

Figure 1a: Map of Edo State Showing Benin City Source: Edo State Ministry of Lands and Surveys, Benin City

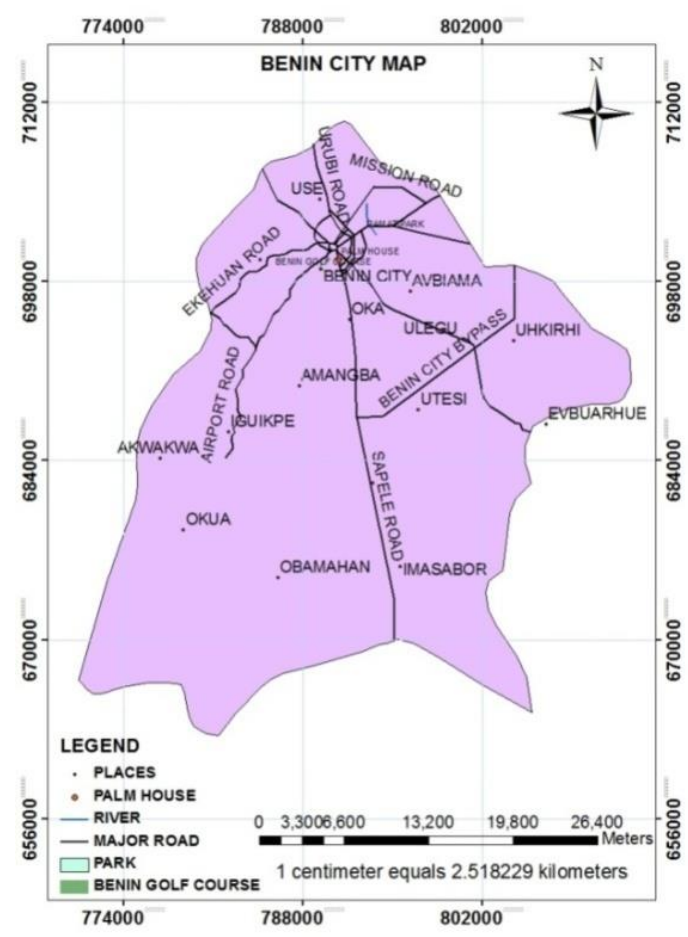

Figure 1b : Map of Benin City

Source: Edo State Ministry of Lands and Surveys, Benin City.

\subsection{Application of Gravimetric Data in Geosciences}

The applications of gravity data set in applied sciences such as geodesy, geodynamics, astronomy, physics and geophysics as given by Dawod (1998) are in Table 1: 
Table 1: Gravimetric Application in Applied Sciences

\begin{tabular}{|c|c|}
\hline Field & Application of Gravimetry \\
\hline Geodesy & $\begin{array}{l}\text { The gravity field modelling is crucial } \\
\text { for deriving geometrically-defined } \\
\text { quantities from the geodetic } \\
\text { observation. } \\
\text { If the distribution of the gravity } \\
\text { values on the surface of the Earth is } \\
\text { known, the shape of this surface may } \\
\text { be determined. } \\
\text { The most important reference } \\
\text { surface for height measurements, the } \\
\text { geoid, is a level surface of the gravity } \\
\text { field. }\end{array}$ \\
\hline Geodynamics & $\begin{array}{l}\text { Temporal gravity changes discovered } \\
\text { by repeated gravity observations } \\
\text { represent important information of } \\
\text { the computation of terrestrial mass } \\
\text { displacement. }\end{array}$ \\
\hline Astronomy & $\begin{array}{l}\text { The terrestrial gravity field is } \\
\text { required for the orbit computation of } \\
\text { natural and artificial celestial bodies. }\end{array}$ \\
\hline Physics & $\begin{array}{l}\text { Gravity is needed in physical } \\
\text { laboratories for the realization of } \\
\text { force standards and derived } \\
\text { quantities. }\end{array}$ \\
\hline Geophysics & $\begin{array}{l}\text { Gravimetric data has essential } \\
\text { information about the density } \\
\text { distribution in the different layers in } \\
\text { the upper crust. }\end{array}$ \\
\hline
\end{tabular}

\subsection{Cost of Gravity Observation and Processing}

As mentioned earlier, the cost of a gravimetric survey is divided into the cost of instruments hiring, cost of observation, cost of labour and cost of data processing. The breakdown of international cost of gravity data acquisition and processing as given by Mariita (2009) consists of two components (Gravity meter rental and consulting services). The cost of instrument hire depends on the type of instrument (gravimeter). The consulting component consists of a gravity survey (data collection only), station surveying, data processing (Bouguer gravity anomalies) and data processing and interpretation (see Table 2).

Table 2: Typical International Costs for Gravity Surveys

\begin{tabular}{|c|c|}
\hline Service & Costs \\
\hline Lravity Meter Rental & $\begin{array}{c}\$ 50-60 / \text { day } \\
\text { plus } \$ 240-270 \\
\text { mobilization }\end{array}$ \\
\hline Lacoste and Romberg model D & $\begin{array}{c}\$ 70-100 / \text { day } \\
\text { plus } \$ 240-270 \\
\text { mobilization }\end{array}$ \\
\hline Scintrex CG3-M Autograv & $\begin{array}{c}\$ 100-130 / \text { day } \\
\text { plus } \$ 240-270 \\
\text { mobilization }\end{array}$ \\
\hline Portable GPS Receivers & $\begin{array}{c}\$ 45-55 / \text { day } \\
\text { plus } \$ 90-110 \\
\text { mobilization }\end{array}$ \\
\hline Consulting Services & \\
\hline Gravity survey (data collection \\
only) & \begin{tabular}{c}
$\$ 1100 /$ day \\
\hline Station surveying
\end{tabular} \\
\hline Data processing and interpretation \\
anomalies)
\end{tabular}

Source: Mariita (2009)

\subsection{Basics of Gravity}

According to SpongIer and Libby (1968), the theory of gravity surveying is directly dependent on Newton's law of gravity. Newton's Law of Gravitation states that between two bodies of known mass the force of attraction $(F)$ is directly proportional to the product of the two masses ( $m_{1}$ and $m_{2}$ ) and inversely proportional to the square of the distance between their centres of mass $\left(r^{2}\right)$ (Ismail, 2015). This implies that the smaller the distance (separation) $(r)$ between the two masses $\left(m_{1}\right.$ and $\left.m_{2}\right)$, the greater the force of attraction between them $\left(m_{1}\right.$ and $\left.m_{2}\right)$ (Equation (1)). 
$F=G \frac{m_{1} m_{2}}{r^{2}}$

Where,

$F=$ Force of attraction, expressed in Newton (N)

$m_{1} m_{2}=$ Masses of the body, expressed in $\mathrm{kg}$

$r=$ Distance between the two masses in metres

$G=6.673 \times 10^{-11} \mathrm{~m}^{3} \mathrm{~kg}^{-1} s^{-2}$ Gravitational constant

From Newton's second law of motion,

$F=m a$

$a=\frac{F}{m}=\frac{F}{m_{1}}=G \frac{m_{1}}{r^{2}}$

But $\quad a=g=G \frac{m}{r^{2}}$

Also, density is mass per unit volume,

$d=\frac{m}{v} \Rightarrow m=d v$

Substituting equation (5) into (4), gives

$g=G \frac{d v}{r^{2}}$

Where, $a=$ Acceleration $\left(\mathrm{ms}^{-2}\right)$

$d=$ Density $\left(\mathrm{kgm}^{-3}\right)$

$v=$ Volume $\left(\mathrm{m}^{3}\right)$

$g=$ Acceleration due to gravity

According to Saibi (2018), the c.g.s unit commonly used in gravity measurement is the milliGal: $1 \mathrm{mGal}=$ $10^{-3} \mathrm{Gal}=10^{-3} \mathrm{~cm} \mathrm{~s}^{-2}=10^{-5} \mathrm{~ms}^{-2}=10 \mu \mathrm{ms}^{-2}$. In gravity surveys, commonly, $\mathrm{mGal}$ is used.

Equation (6) implies according to Spongler and Libby (1968) that the value of gravity is directly proportional to the product of density and volume of a mass (earth materials beneath the gravimeter) and inversely proportional to the square of the distance from the attractive body. As the earth is not perfectly homogeneous, spatial variations of gravity are also a function of latitude and the adjacent terrain. At the equator, the value of gravitational acceleration on Earth's surface varies from $9.78 \mathrm{~m} / \mathrm{s}^{2}$ to about 9.83 $\mathrm{m} / \mathrm{s}^{2}$ at the poles (Figure 2) (Ismail, 2015).

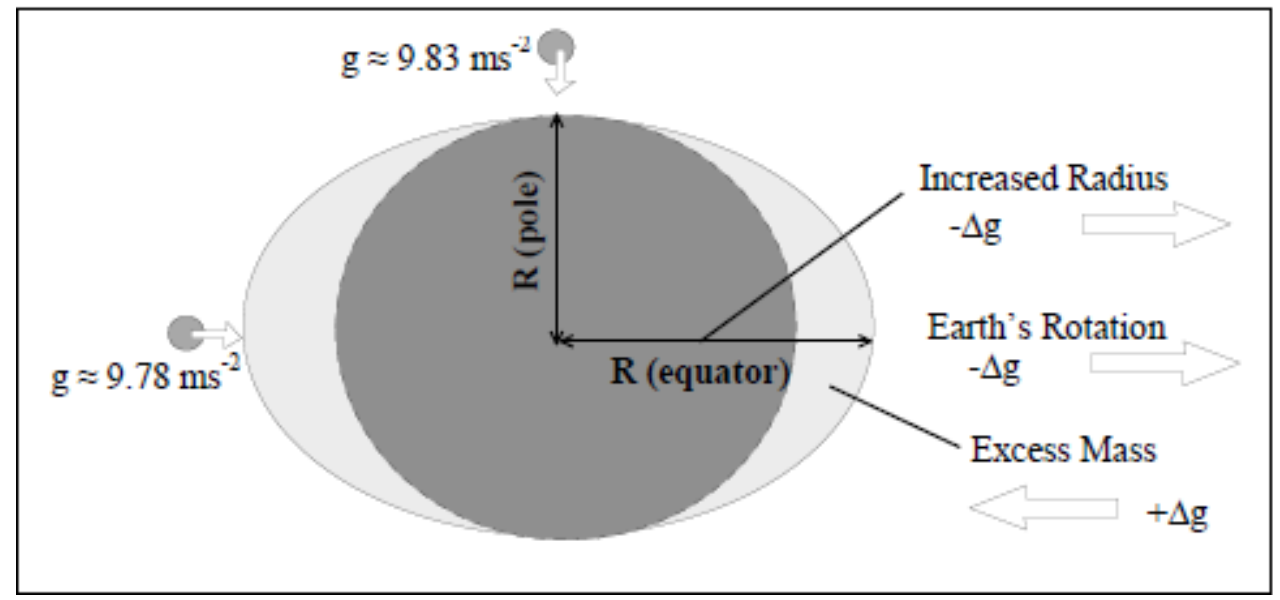

Figure 2: Gravity at the Equator and the Pole Source: Ismail (2015)

\subsection{Corrections to Gravity Observations}

\subsubsection{Tide Correction}

According to Valenta (2015), the tidal correction accounts for the gravity effect of Sun, Moon and large planets. Modern gravity meters compute the tide effects automatically. These background variations can be corrected for using a predictive formula (Equation (7)) which utilises the gravity observation position and time of observation (Mathews and McLean, 2015).

$r_{t}=r_{c}+g_{\text {tide }}$

Where,

$r_{t}=$ Tide correction reading in $\mu \mathrm{ms}^{-2}$

$r_{c}=$ Scale factor correction reading in $\mu \mathrm{ms}^{-2}$ 
$g_{\text {tide }}=$ Earth Tide Correction (ETC) in $\mu \mathrm{ms}^{-2}$

\subsubsection{Drift Correction}

Gravimeters are very sensitive instruments. Temperature changes and elastic creep in springs cause meter readings to change gradually with time even if the meter is never moved (Saibi, 2018). Mathews and McLean (2015) also explained that the most common cause of instrument drift is due to the extension of the sensor spring with changes in temperature (obeying Hooke's law). To calculate and correct for daily instrument drift, the difference between the gravity control station readings (closure error) is used to assume the drift and a linear correction is applied as given in equation (8) (Mathews and McLean, 2015).

$I D=r_{c s 2}-r_{c s 1} / t_{c s 2}-t_{c s 1}$

Where,

ID = Instrument drift in $\mu \mathrm{ms}^{2} /$ hour

$r_{c s 2}=$ Control station second reading in $\mu \mathrm{ms}^{-2}$

$r_{c s 1}=$ Control station first reading in $\mu \mathrm{ms}^{-2}$

$t_{c s 2}=$ Control station second time

$t_{c s 1}=$ Control station first time

\subsubsection{Atmospheric Correction}

As stated by Mathews and McLean (2015), the gravity effect of the atmosphere above the reference datum can be calculated with an atmospheric model and is subtracted from the normal gravity. The model for the computation of the atmospheric correction is

$A C=8.74-0.00099 . H+0.0000000356 . H^{2}(9)$ Where,

$\mathrm{AC}=$ Atmospheric correction in gravity units

$\mathrm{H}=$ Elevation above the reference datum in metres

\subsubsection{Free Air Correction}

If the gravity station is located in height $H$ above the reference surface, typically mean sea level, the free air reduction considers the decrease of gravity with increasing heights. If the earth is considered as a point mass, its gravity will decrease inversely with the square of the distance to the earth's centre of mass. The formula to calculate the magnitude of the reduction in practise is

$$
\begin{aligned}
g_{F A} & =-\frac{2 g}{r} H_{s}=-308.6 H \mu G a l \\
& =-0.3086 \mathrm{HmGal}
\end{aligned}
$$

Where,

$H=$ Station orthometric height in metres

$g=$ Mean value of gravity $(980500 \mathrm{mGal})$

$r=$ Mean radius of the Earth

\subsubsection{Bouguer Correction}

Free-air correction does not take into account the mass of rock between measurement station and sea level. The Bouguer correction, $g_{F A}$, accounts for the effect of the rock mass by calculating extra gravitational pull exerted by rock slab of thickness $h$ and mean density $\rho$ (Saibi, 2018). To compute the Bouguer correction, equation (11) (Nasuti et al., 2010) is applied.

$g_{B}=2 \pi G \rho H_{s}=0.0419 \rho H \mathrm{mGal}$

Where,

$\rho=$ Density $=2670 \mathrm{~kg} / \mathrm{m}^{3}$ (Märdla et al., 2017)

$G=$ Universal gravitational constant

$H=$ Station orthometric height in metres

\subsubsection{Elevation Correction}

The combination of the free air and the Bouguer Corrections gives the elevation correction $\left(g_{E C}\right)$. It is computed using

$$
\begin{aligned}
g_{E C} & =-\left[\frac{2 g}{r}-2 \pi G \rho\right] H_{s} m G a l \\
& =-(0.3086-0.0419 \rho) H m G a l
\end{aligned}
$$

\subsubsection{Terrain Correction}

The terrain correction accounts for variations in gravity values caused by variations in topography near the observation point. The correction accounts for the attraction of material above the assumed spherical cap and for the over-correction made by the Bouguer correction when in valleys. The terrain correction is positive regardless of whether the local topography 
consists of a mountain or a valley (Mathews and McLean, 2015). The method of computing terrain corrections is very tedious. It requires the application of the software that makes use of digital terrain models (DTM) available from government or thirdparty sources.

\subsection{Normal Gravity}

The normal or theoretical gravity value at a geographic location is calculated using the assumption that the Earth is a regular homogeneous ellipsoid of rotation (the reference ellipsoid) (Murray and Tracey,
2001). Gravity values vary with latitude as the earth is not a perfect sphere and the polar radius is much smaller than the equatorial radius. The effect of centrifugal acceleration is also different at the poles versus the equator (Mathews and McLean, 2015). The closed-form of the Clarke 1880 ellipsoid Gravity Formula is used to approximate the theoretical gravity at each station location and essentially produce a latitude correction in this study. The model for the computation of theoretical gravity on the Clarke 1880 ellipsoid whose derivation details are given by Eteje et al. (2019) is

$$
g_{\text {T Clarkd } 880}=9.780519381\left[\frac{\left(1+0.00182202113732433 \sin ^{2} \phi\right)}{\left(1-0.00680351145465242 \sin ^{2} \phi\right)^{1 / 2}}\right] \mathrm{ms}^{-2}
$$

Where,

$g_{\text {TClarkd } 880}=$ Theoretical gravity on the Clarke ellipsoid

$\phi=$ Station latitude

\subsection{Gravity Anomaly}

The gravity anomaly $\Delta g$, is the difference between the observed gravity value $(g)$ reduced to the geoid, and a normal, or theoretical, computed gravity value $\left(\gamma_{o}\right)$ at the mean earth ellipsoid, where, the actual gravity potential on the geoid equal the normal gravity potential at the ellipsoid, at the projection of the same terrain point on the geoid and the ellipsoid respectively, that is (Dawod, 1998)

$\Delta g=g-\gamma_{o}$

Considering the nature of the topography of the earth surface, which is irregular in shape, there are two basic types of gravity anomalies (free air and Bouguer anomalies).

\subsubsection{Free Air Gravity Anomaly}

Free air gravity anomaly is obtained by applying the free air correction to the difference between the observed gravity reduced to the geoid and the theoretical gravity computed on a specified ellipsoid. The model for the computation of the free air anomaly as given by Murray and Tracey (2001) is
$\Delta g_{F A}=\left(g_{\text {Obs }}-\gamma_{o}+0.3086 H\right) \mathrm{mGal}$

Where,

$\Delta g_{F A}=$ Free air anomaly

$g_{\text {obs }}=$ Observed gravity

$\gamma_{o}=$ Theoretical/Normal gravity

$H=$ Orthometric height

\subsubsection{Bouguer Gravity Anomaly}

There are two types of Bouguer Gravity Anomaly: the simple and the complete Bouguer gravity anomalies. In simple Bouguer gravity anomaly computation, the topographic/terrain effect is not considered. The simple Bouguer gravity anomaly is obtained by applying the Bouguer correction only to the free air gravity anomaly. The model for the computation of the simple Bouguer gravity anomaly is given by Murray and Tracey (2001) as

$\Delta g_{S B}=\left(\Delta g_{F A}-0.0419 \rho H\right) \mathrm{mGal}$

Where,

$\Delta g_{S B}=$ Simple Bouguer gravity anomaly

$\rho=$ Density

The complete Bouguer gravity anomaly computation is done by applying the terrain correction to the simple Bouguer gravity anomaly. Mathews and 
McLean (2015) gave the model for the computation of the complete Bouguer gravity anomaly as

$$
\Delta g_{C B}=\left(\Delta g_{S B}+T C\right) \mathrm{mGal}
$$

Where,

$\Delta g_{C B}=$ Complete Bouguer gravity anomaly

$T C=$ Terrain correction

\subsection{Kriging Method of Interpolation}

Kriging is an interpolation method that can produce predictions of unobserved values from observations of its value at nearby locations. Kriging confers weights for each point according to its distance from the unknown value. Actually, these predictions treated as weighted linear combinations of the known values (Jassim and Altaany, 2013). Kriging method is more accurate whenever the unobserved value is closer to the observed values (Van-Beers and Kleijnen, 2003; Jassim and Altaany, 2013). The effectiveness of Kriging depends on the correct specification of several parameters that describe the semivariogram and the model of the drift (i.e., does the mean value change over distance). Because Kriging is a robust interpolator, even a naive selection of parameters will provide an estimate comparable to many other grid estimation procedures. According to Ozturk and Kilic (2016), the basic equation used in the Ordinary Kriging is

$\hat{Z}\left(s_{o}\right)=\sum_{i=1}^{N} \lambda_{i} Z\left(s_{i}\right)$

Where,

$Z\left(s_{i}\right)=$ Measured value at the $i$ th location

$\lambda_{i}=$ Unknown weight for the measured value at the $i$ th location

$\left(s_{o}\right)=$ Estimation location

$\mathrm{N}=$ Number of measured values

With Kriging method, the value $\hat{Z}\left(s_{o}\right)$ at the point $s_{o}$, where the true unknown value is $Z\left(s_{o}\right)$, is estimated by a linear combination of the values at $N$ surrounding data points (Borga and Vizzaccaro 1996; Ozturk and Kilic, 2016). This study applies the kriging interpolation method to plot the gravity anomalies contour maps using Surfer 12 software.

\subsection{Polynomial Interpolation}

For the polynomial interpolation method, it is necessary to determine a polynomial that has the property to go through some data points by using different methods. This method is used to determine the general trend of the values of a polynomial function $z=f(x, y)$ for a certain area. Polynomials can vary for the number of the degree, representing different geometric surfaces: a plane, a bilinear surface (etc.) quadrant area, a cubic surface, another appropriately defined area. In addition to the variables $(\mathrm{x}, \mathrm{y})$, the maximum power of the polynomial equation of these variables may represent other parameters (Dumitru et al., 2013). The example of the use of the interpolation method in gravimetric study is that of Kaye (2012) who applied the polynomial interpolation method for interpolation of gravitational waveform. The general form of a spatial surface defined by a polynomial of order $n+m$ is (Dumitru et al., 2013.

$$
\begin{aligned}
f(x, y)= & a_{00}+a_{10} x+a_{01} y+a_{11} x y+a_{20} x^{2}+ \\
& a_{02} y^{2}+a_{30} x^{3}+a_{21} x^{2} y+a_{12} x y^{2}+ \\
& a_{03} y^{3}+\ldots+a_{m n} x^{m} y^{n}
\end{aligned}
$$

Where,

$a_{m n}=$ Coefficients of the variables $(x, y)$

$m=$ Degree of $x$ the function $\mathrm{f}(\mathrm{x}, \mathrm{y})$

$n=$ degree of the variable $y$ of the function $\mathrm{f}(\mathrm{x}, \mathrm{y})$

Equation (19) is a polynomial of order $m+n$ which describes the tendency of a surface determined by a set of $m+n+1$ points. According to Eteje et al. (2019), the accuracy of the polynomial surface is highest when the number of observation points is equal to the number of the model terms. Since 22 points were chosen and the fifth-degree polynomial surface has 22 terms, the fifth-degree polynomial model was chosen. The fifth-degree polynomial interpolation model given by Eteje et al. (2019) is 


$$
\begin{aligned}
N=a_{0}+a_{1} X+a_{2} Y+a_{3} X Y+a_{4} X^{2}+a_{5} Y^{2}+a_{6} X^{2} Y^{2}+a_{7} X^{2} Y+ & \\
& a_{8} X Y^{2}+a_{9} X^{3}+a_{10} Y^{3}+a_{11} X^{3} Y+a_{12} X^{3} Y^{2}+a_{13} X^{2} Y^{3}+ \\
& a_{14} X Y^{3}+a_{15} X^{4}+a_{16} Y^{4}+a_{17} X^{4} Y+a_{18} X Y^{4}+a_{19} X^{5}+a_{20} Y^{5}
\end{aligned}
$$

Where,

$Y=A B S\left(y-y_{o}\right)$

$X=A B S\left(x-x_{o}\right)$

$y=$ Latitude of observed station

$x=$ Longitude of observed station

$y_{o}=$ Latitude of the origin (average of the Latitudes)

$x_{o}=$ Longitude of the origin (average of the Longitudes)

\subsection{Observation Equation Method of Least Squares} Adjustment

The fitting of polynomial interpolation surface to a set of gravity data/anomalies requires the model parameters (variable coefficients) to be computed. The computation of these coefficients is done by observation equation method of least squares adjustment technique. The functional relationship between adjusted observations and the adjusted parameters as given by Eteje and Oduyebo (2018) is:

$$
L_{a}=F\left(X_{a}\right)
$$

Where, $L_{a}=$ adjusted observations and $X_{a}=$ adjusted parameters. Equation (21) is a linear function and the general observation equation model was obtained. The system of observation equations is presented by matrix notation as (Ono et al., 2018):

$$
V=A X-L
$$

Where,

$A=$ Design Matrix,

$X=$ Vector of Unknowns

$L=$ Observation Matrix.

$V=$ Residual

The residual, $V$ which is the difference between the estimate and the observation is usually useful when applying least squares adjustment technique for the determination of gravity anomaly interpolation model parameters since it is equal to the difference between the model gravity anomaly and the computed gravity anomaly of the points. So, it can be used as a check. The unknown/model parameter is computed as $X=\left(A^{T} A\right)^{-1} A^{T} L$

Where,

$\left(A^{T} A\right)^{-1}=$ Inverse of the normal matrix

The step by step procedures for the computation of the polynomial interpolation model Coefficients $\left(a_{m n}\right)$ of the variables $(x, y)$ are detailed in Eteje and Oduyebo (2018).

\subsection{Reliability of the Model}

The reliability/accuracy of the gravity interpolation model is obtained using the Root Mean Square Error, RMSE index. To evaluate the reliability of the model accuracy, the gravity anomalies of the points from the model are compared with their corresponding computed gravity anomalies from the processed gravity observations to obtain the gravity anomaly residuals. The gravity anomaly residuals and the total number of selected points are used for the computation of the RMSE, as well as the accuracy of the model. The Root Mean Square Error, RMSE index for the computation of the gravity interpolation model accuracy as given by Yilmaz and Kozlu (2018) is

$$
R M S E= \pm \sqrt{\frac{1}{n} \sum_{i=1}^{n}\left(\delta \Delta g_{\text {Residual }}\right)^{2}}
$$

Standard error (SE) is another measure of accuracy/reliability and it computed as

$$
S E= \pm \sqrt{\frac{1}{n-1} \sum_{i=1}^{n}\left(\delta \Delta g_{\text {Residual }}\right)^{2}}
$$

Where,

$$
\begin{aligned}
& \left.\delta \Delta g_{\text {Residual }}=\Delta g_{\text {Computed }}-\Delta g_{\text {Model }}\right) \\
& \Delta g_{\text {Computed }}=\text { Computed gravity anomaly } \\
& \Delta g_{\text {Model }}=\text { Model gravity anomaly } \\
& \mathrm{n}=\text { Number of Points }
\end{aligned}
$$




\section{METHODOLOGY}

The adopted methodology is divided into station selection; data acquisition which consists of GNSS and gravity observations; data processing which comprises processing of the GNSS and the gravity observations and results presentation and analysis which also consists of the presentation and analysis of the processed GNSS and gravity observations.

\subsection{Station Selection}

A total of 22 points were used in the study. The points consisted: 1 reference station at the Benin City Airport whose absolute gravity value was known and 21 new points which were chosen along the major roads of the City. The roads which the chosen points affected are: Ring Road (RR), Sapele Road (SR), Airport Road (AR), Ekeuan Road (EK), Siluko Road (SLK), Mission Road (MR), Aduwawa Road (AD), First East Circular Road (UU), Urubi Road (UU), Uselu Road (UU), and Akpakpava-Agbor Road (AK) (see Figure 3). The chosen points also included 2 primary control stations (XSU92 located at Edo College and XSU100 located within the School of Nursing premises, along Sapele Road). The points were chosen knowing quite full well that their spatial distribution would not affect the accuracy of the models, opined by Oluyori and Eteje (2019).

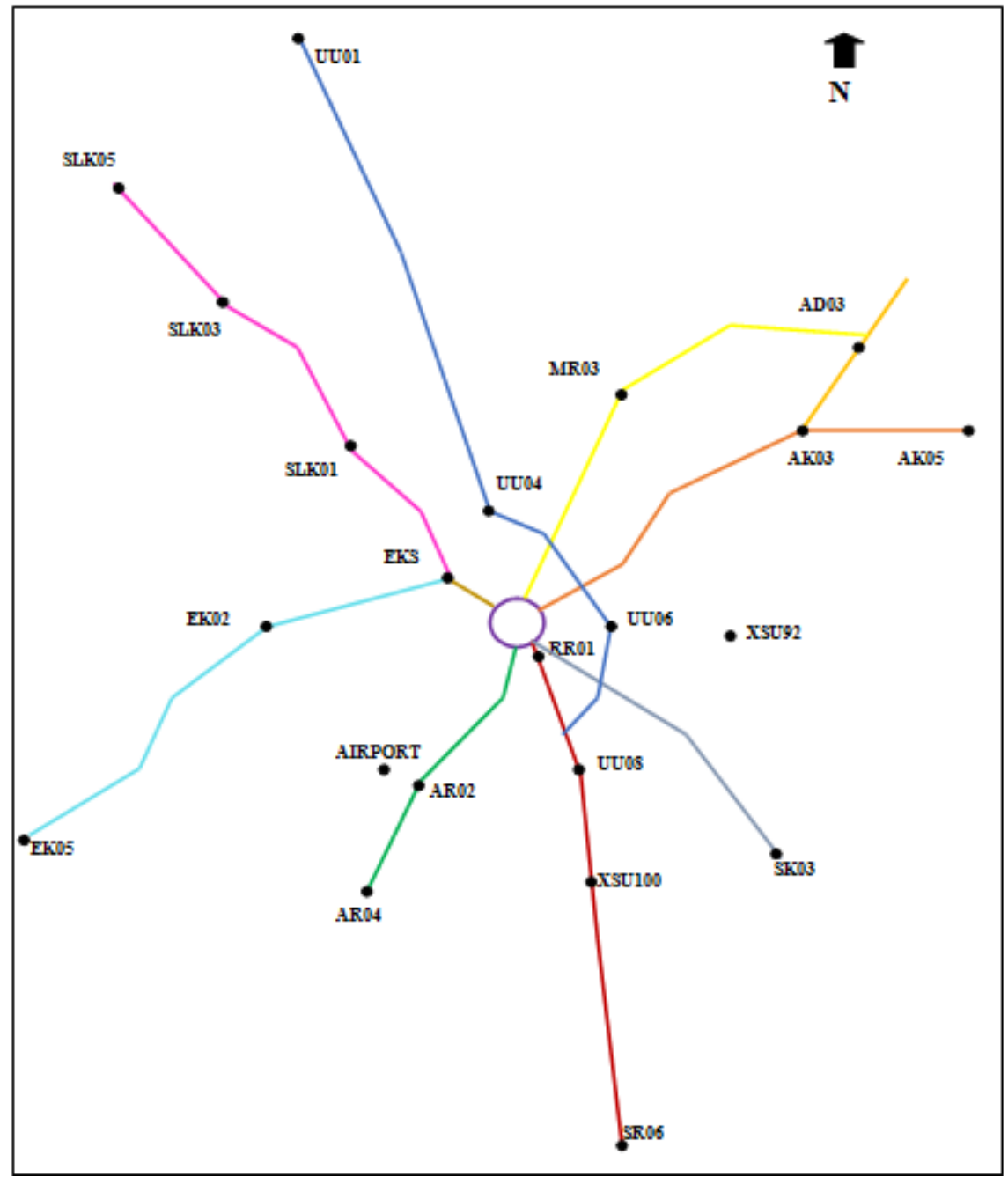

Figure 3: Selected/Observed Points Network (Not to Scale) 


\subsection{Data Acquisition}

The data acquisition stage consisted of the GNSS and the gravity observations.

\subsection{GNSS Observation}

The GNSS observation was carried out using five CHC 900 dual frequency receivers to obtain the coordinates of the chosen points. During the observation, the base receiver was set at the first order control station (XSU 92) which was located at Edo College (see Figure 4) and the rover receivers were set at the new points (see Figure 5).

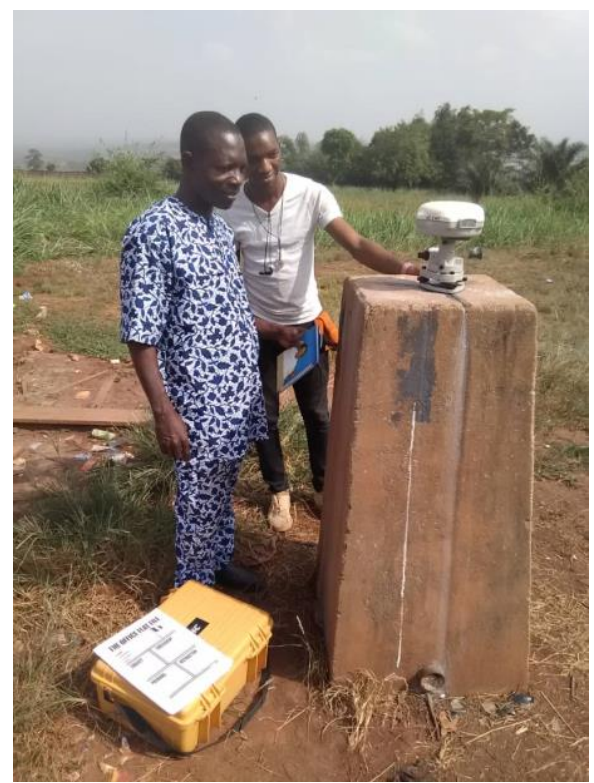

Figure 4: Base Receiver at Control Station XSU92

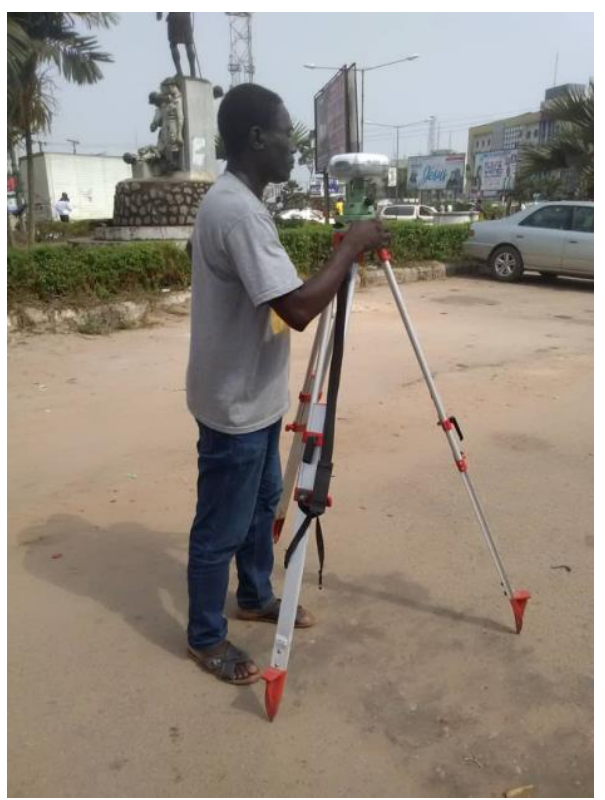

Figure 5: Rover Receiver at One of the Chosen Points at the Frontage of Central Baptist Church, Ring Road

\subsection{Gravity Observation}

The gravity observation was done to obtain the gravimetric data of the chosen points. The observation was carried out in seven different loops with SCINTREX CG-5 Autograv (The accuracy of the meter as given by Lederer (2009) is $2.1 \pm 1.1 \mu \mathrm{Gal})$. Each loop observation started from and closed on the reference station at the Benin City Airport (see Figures 6, 7 and 8). The observation was carried out by an expert (a Geophysicist from Mountain Top University, Ogun State).

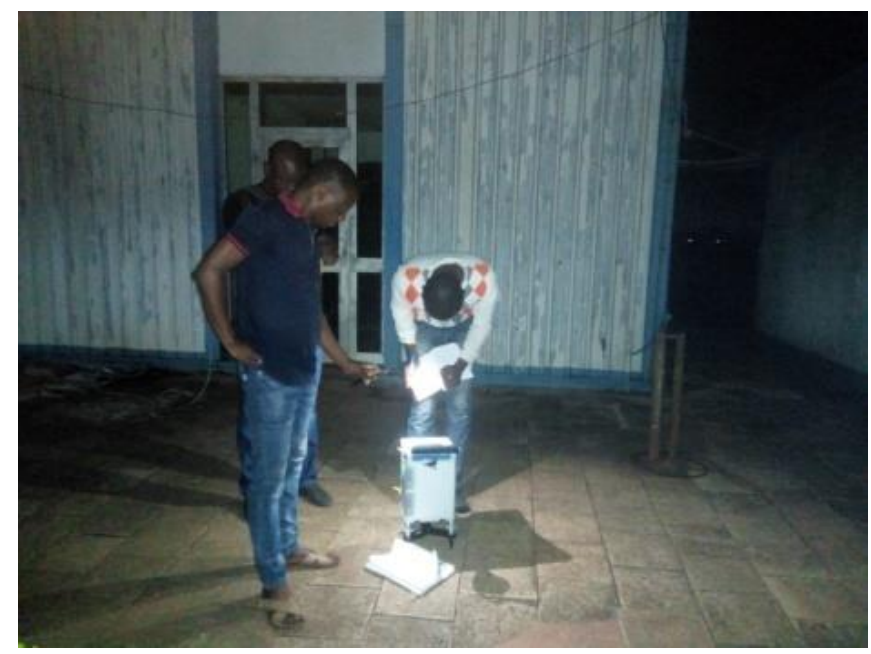

Figure 6: Gravimeter at Reference Station (Benin City Airport)

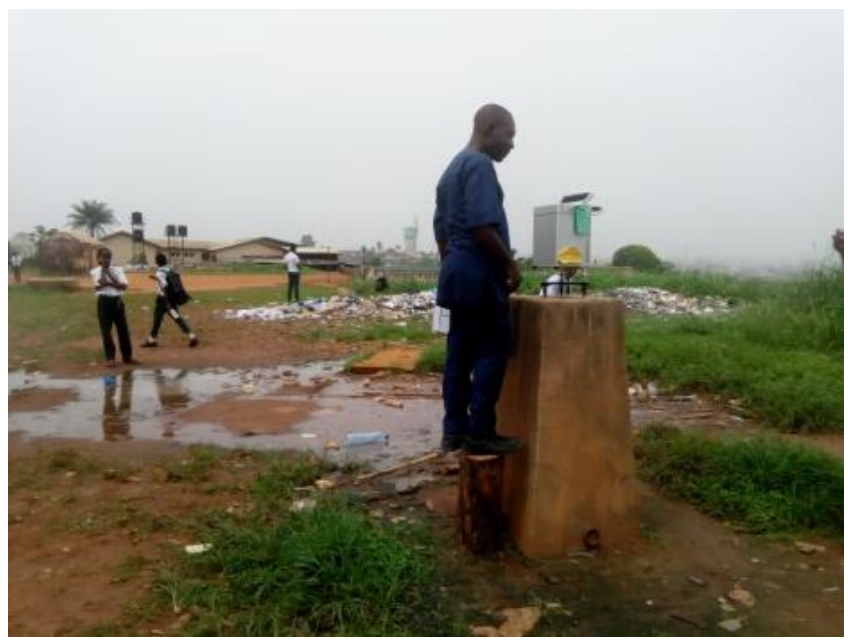

Figure 7: Gravimeter at Control Station XSU92 


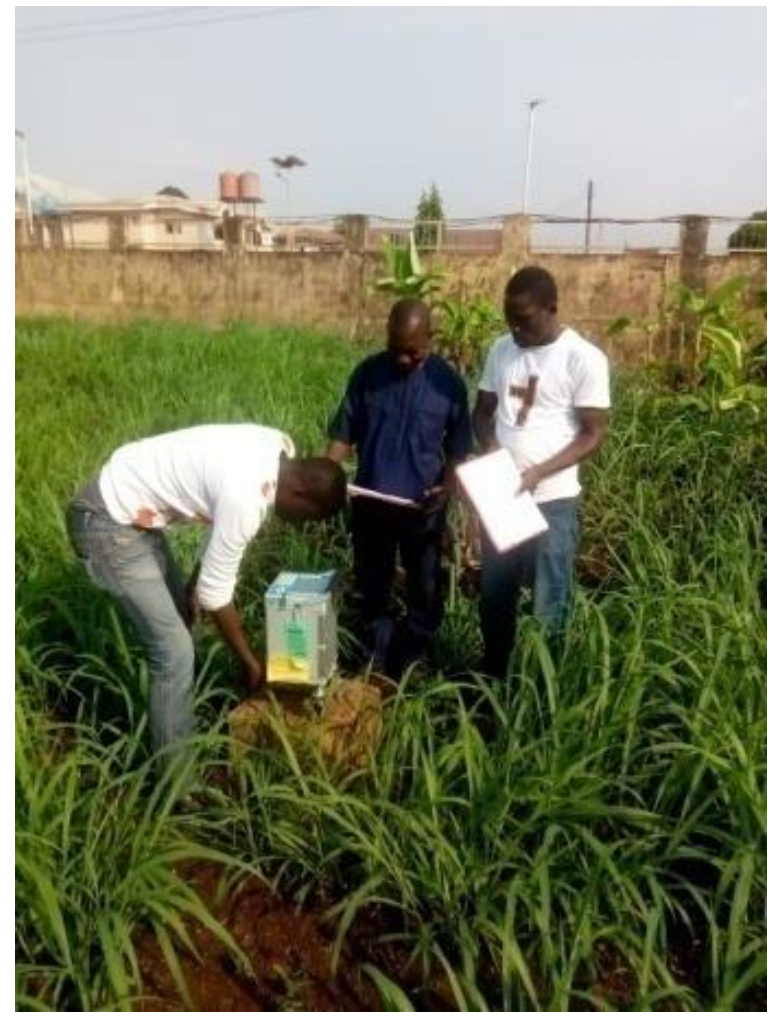

Figure 8: Gravimeter at Station XSU100

\subsection{Data Processing}

The GNSS observations were processed using Compass Post-processing software in Minna datum to obtain the coordinates of the points. The gravity observations were processed using gravity processing software. The processing was also done by the Geophysicist to obtain the free air and the simple Bouguer gravity anomalies of the points. The normal gravity values of the points were computed using equation (13). The tide, drift, atmospheric, free air and Bouguer corrections were respectively computed using equations (7) to (11). The gravity anomalies were computed with equation (14) while the free air and the Bouguer gravity anomalies were respectively computed using equations (15) and (16)

\subsection{Fitting of the Polynomial Interpolation Surface to the Computed Gravity Anomalies}

The fifth-degree polynomial interpolation surface (equation (20)) was fitted to the free air and the Bouguer gravity anomalies to enable free air and Bouguer gravity anomalies of points within Benin City to be determined by interpolation. The fitting was done with least squares technique by computing the models (free air and Bouguer gravity anomalies models) parameters, as well as the variable coefficients using equation (23). The free air and the Bouguer gravity anomalies interpolation models parameters are computed as:

$$
\begin{aligned}
& \text { Free Air Gravity Anomalies Model Parameters }
\end{aligned}
$$

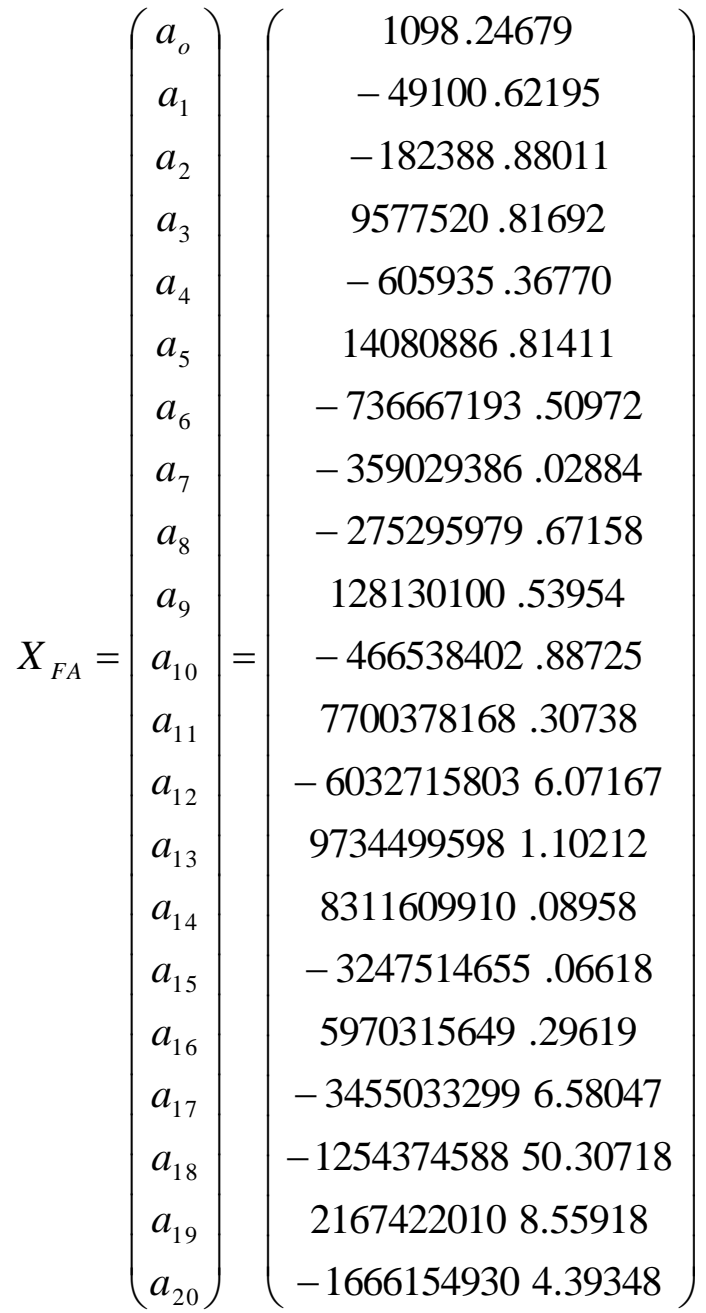




\section{Bouguer Gravity Anomalies Model Parameters}

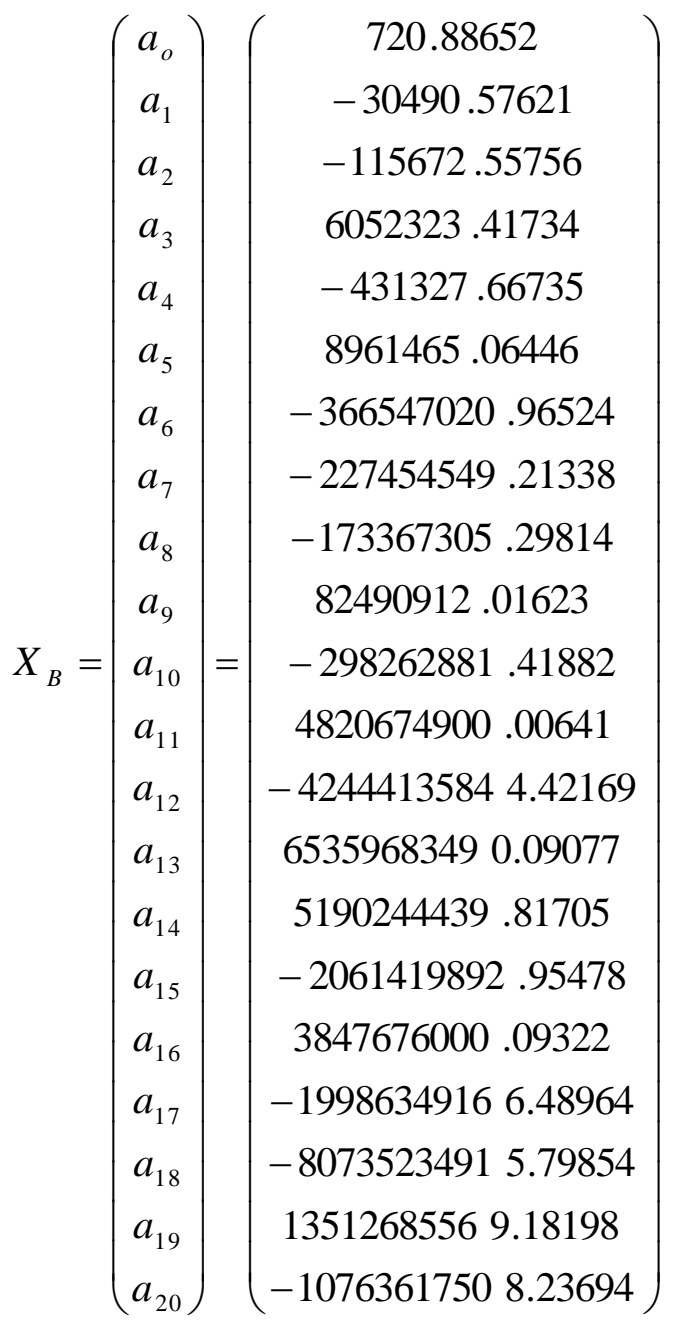

The computed free air and Bouguer gravity anomalies model parameters, as well as the variable coefficient, were substituted accordingly into equation (20) and Microsoft Excel programs were developed for the two models. Using the two models, the free air and Bouguer gravity anomalies of the points were obtained by interpolation. And this is known as the model gravity anomaly.

The reliability, as well as the RMSE and the standard errors of the two models, were respectively computed using equations (24) and (25).

\section{RESULTS PRESENTATION AND ANALYSIS}

Figures 9 and 10 respectively show the contour plots of the computed and the model free air gravity anomalies. This was done to present graphically the fit of the polynomial surface to the computed free air gravity anomalies. The dependability of an interpolation model is its ability to reproduce exactly the values of the gravity anomalies of the points to which the surface was fitted. It can be seen from Figures 9 and 10 that the contour plots of the computed and the model free air gravity anomalies are truly identical in shape which implies the high degree of consistency of the model.

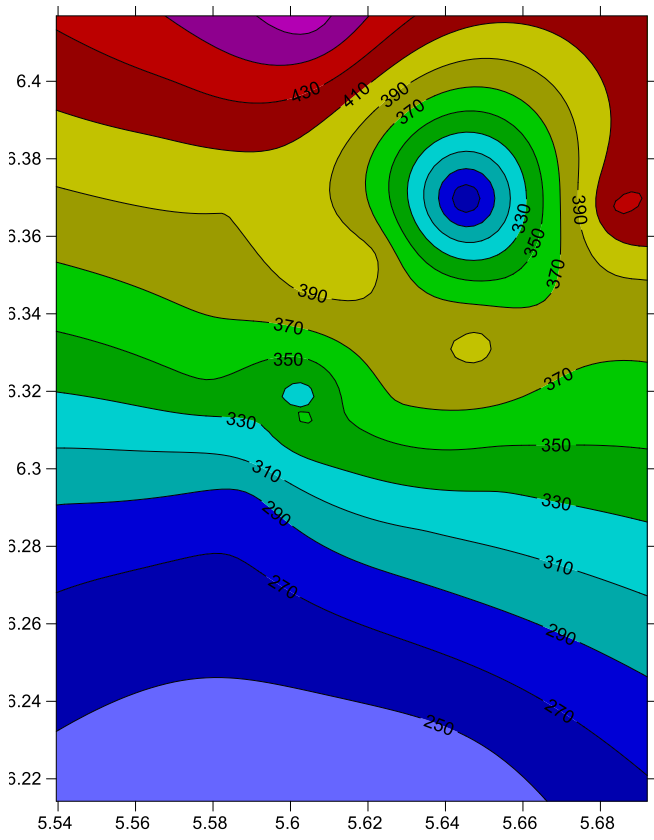

Figure 9: Contour Plot of Computed Free Air Gravity

Anomalies

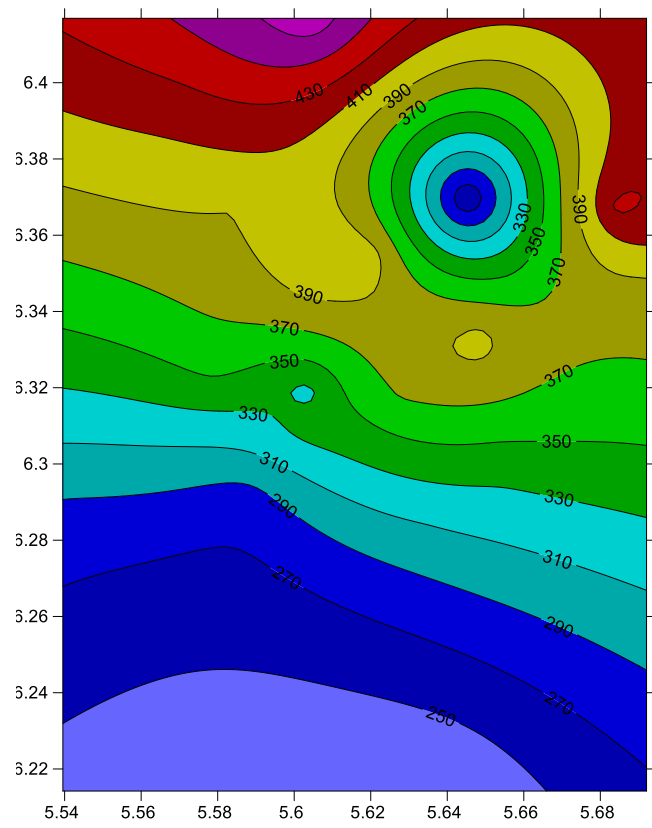

Figure 10: Contour Plot of Model Free Air Gravity Anomalies 
Again, Figure 11 presents the plot of the computed and the model free air gravity anomalies of the chosen points. This was also done to show graphically the agreement between the computed and the model free air gravity anomalies, as well as the fit of the interpolation surface to the computed free air gravity anomalies. It can also be seen from Figure 11 that the plotted computed and the model free air gravity anomalies have identical shapes. This again shows the high dependability of the model.
Again, Figure 11 presents the plot of the computed and the model free air gravity anomalies of the chosen points. This was also done to show graphically the agreement between the computed and the model free air gravity anomalies, as well as the fit of the interpolation surface to the computed free air gravity anomalies. It can also be seen from Figure 11 that the plotted computed and the model free air gravity anomalies have identical shapes. This again shows the high dependability of the model.

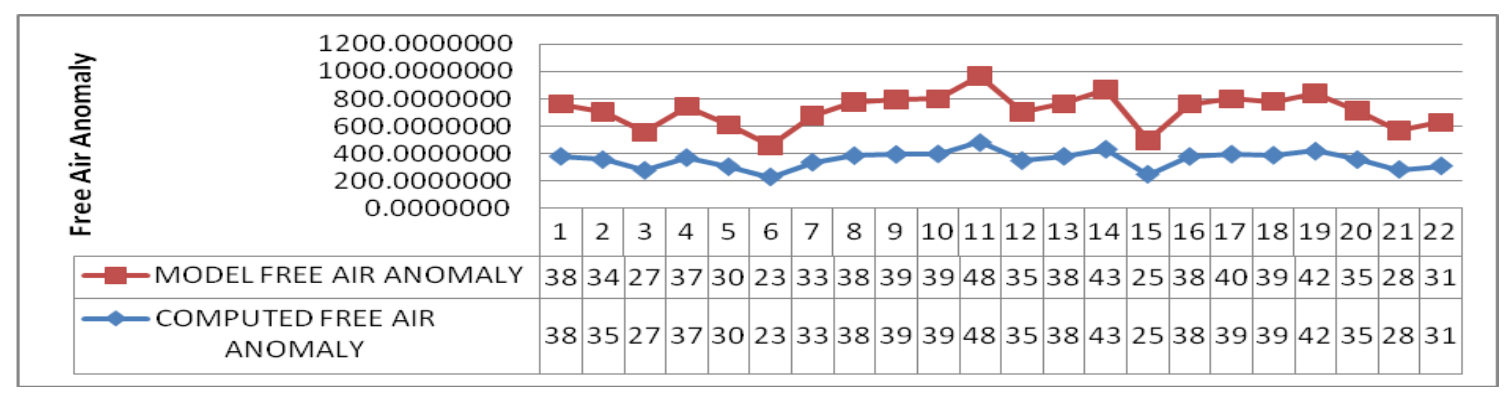

Figure 11: Plot of the Computed and Model Free Air Gravity Anomalies

Figures 12 and 13 respectively present the contour plots of the computed and the model Bouguer gravity anomalies. This was also done to show graphically the fit of the polynomial surface to the computed Bouguer gravity anomalies. It can again be seen from Figures 12 and 13 that the contour plots of the computed and the model Bouguer gravity anomalies are truly identical in shape which implies the high degree of consistency of the model.

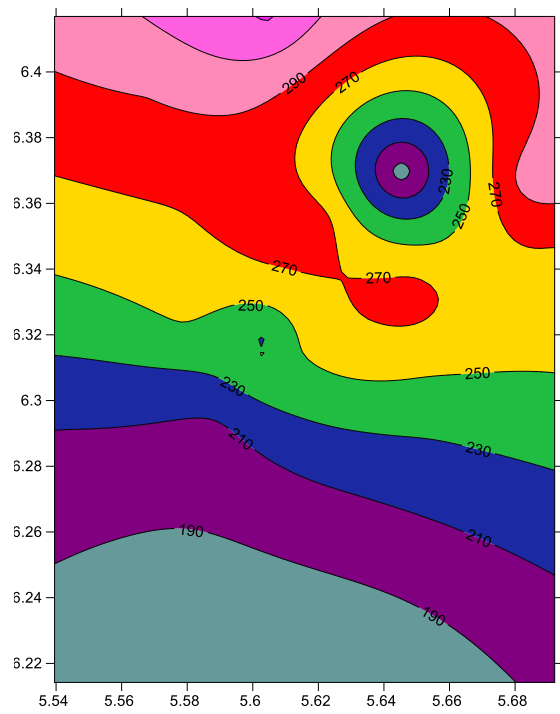

Figure 12: Contour Plot of Computed Bouguer Gravity Anomalies

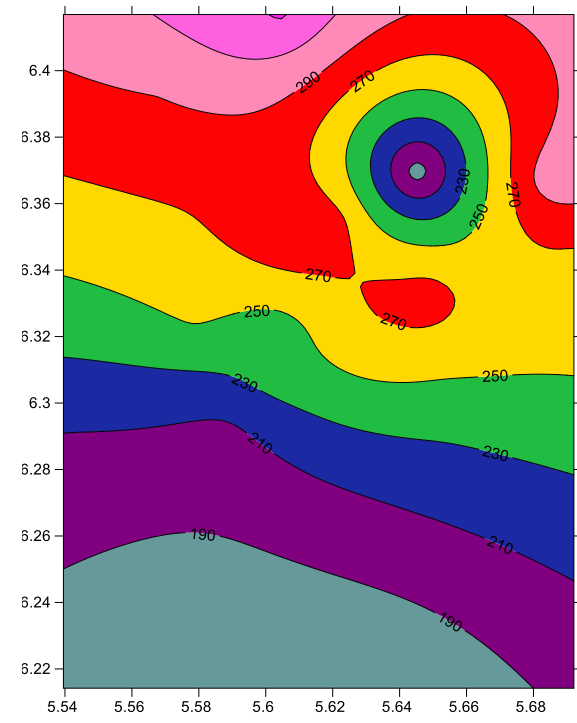

Figure 13: Contour Plot of Model Bouguer Gravity Anomalies

Also, Figure 14 presents the plot of the computed and the model Bouguer gravity anomalies of the observed points. This was as well done to show graphically the agreement between the computed and the model Bouguer gravity anomalies, as well as the fit of the interpolation surface to the computed Bouguer gravity anomalies. It can as well be seen from Figure 14 that the plotted computed and the model free air gravity 
anomalies have identical shapes. This also shows the high reliability of the model.

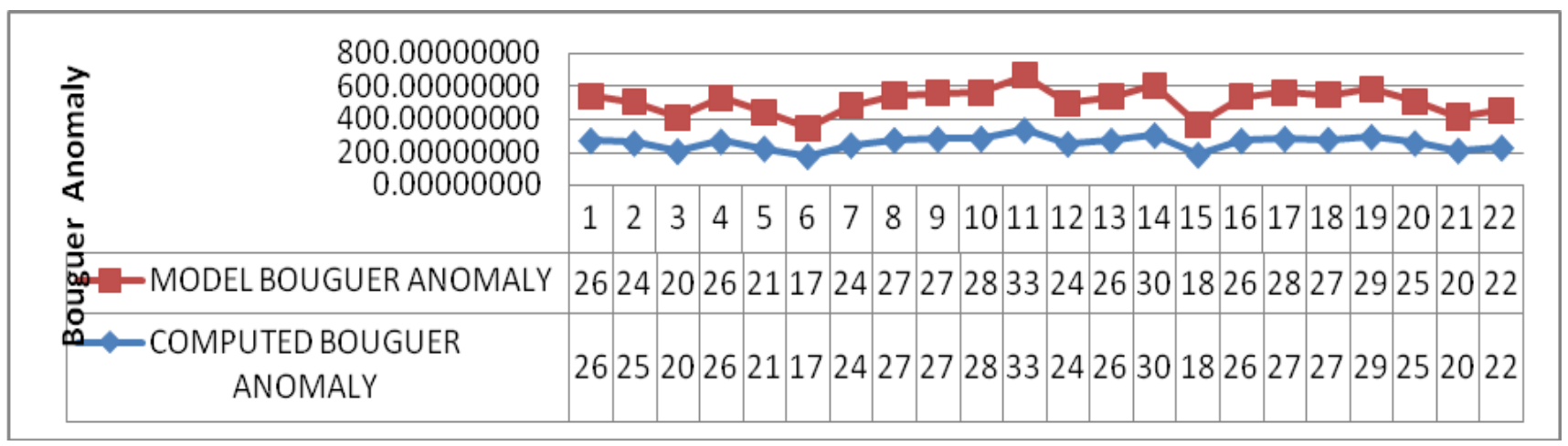

Figure 14: Plot of the Computed and Model Free Air Gravity Anomalies

Figure 15 presents the plot of the model free air and (free air and Bouguer gravity anomalies) models are the Bouguer gravity anomalies. This was done to identical in shape. This implies that the two models compare the shape of the surfaces of the two models. are representing the same terrain/topography.

From Figure 15 it is seen that the surfaces of the two

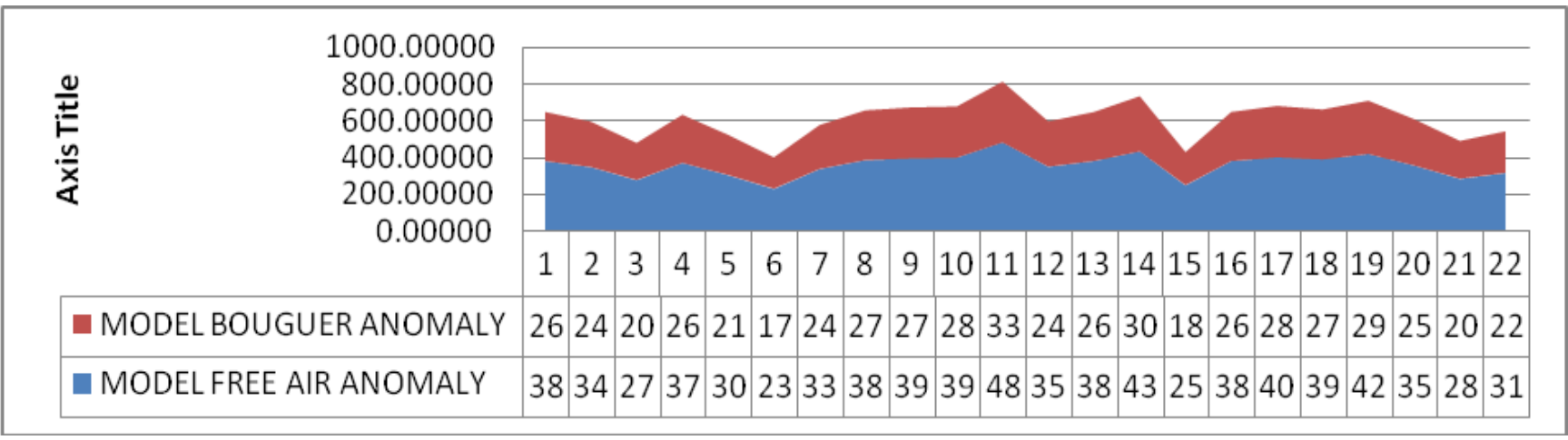

Figure 15: Plot of the Free Air and the Bouguer Model Gravity Anomalies

Table 3 presents the minimum and the maximum model free air and Bouguer gravity anomalies in $\mathrm{mGal}$. This was done to present the ranges within which free air and Bouguer gravity anomalies can be determined by interpolation in Benin City using the two models. It can be seen from Table 3 that the minimum and the maximum model free air and Bouguer gravity anomalies are respectively $230.13943 \mathrm{mGal}$ and $483.43279 \mathrm{mGal}$, and $171.82527 \mathrm{mGal}$ and $332.57248 \mathrm{mGal}$. This implies that free air and Bouguer gravity anomalies can be respectively interpolated with the models within the ranges of $230.13943 \mathrm{mGal}$ to $483.43279 \mathrm{mGal}$ and $171.82527 \mathrm{mGal}$ to $332.57248 \mathrm{mGal}$.
Table 3: Minimum and Maximum Model Free Air and Bouguer Gravity Anomalies

\begin{tabular}{|c|c|c|}
\hline $\begin{array}{c}\text { MODEL } \\
\text { GRAVITY } \\
\text { ANOMALY }\end{array}$ & $\begin{array}{c}\text { MINIMUM } \\
\text { (mGal) }\end{array}$ & $\begin{array}{c}\text { MAXIMUM } \\
\text { (mGal) }\end{array}$ \\
\hline FREE AIR & 230.13943 & 483.43279 \\
\hline BOUGUER & 171.82527 & 332.57248 \\
\hline
\end{tabular}

Table 4 shows the computed free air and Bouguer anomalies models RMSE and standard errors. This was done to present the reliability, as well as the accuracy of the two (free air and Bouguer) gravity anomaly interpolation models. From Table 4, it can be seen that the RMSE and the standard error of the free air gravity anomaly model are respectively $2.331 \mathrm{mGal}$ 
$\left(2.331 \times 10^{-5} \mathrm{~ms}^{-2}\right)$ and $2.385 \mathrm{mGal}\left(2.385 \times 10^{-5} \mathrm{~ms}^{-2}\right)$ while those of the Bouguer gravity anomaly model are respectively $1.453 \mathrm{mGal} \quad\left(1.453 \times 10^{-5} \mathrm{~ms}^{-2}\right)$ and $1.487 \mathrm{mGal}\left(2.331 \times 10^{-5} \mathrm{~ms}^{-2}\right)$. The obtained accuracy for the two models agree with the ones achieved by Dawod (1998), Cattin et al. (2015), and Yilmaz and
Kozlu (2018) in their studies. This shows the high reliability, as well as dependability of the models. The high reliability of the models resulted from the fifthdegree polynomial model, whose number of terms is equal to the of the observation points as detailed in Eteje et al. (2019).

Table 4: Computed Free Air and Bouguer Anomalies Models RMSE and Standard Errors

\begin{tabular}{|c|c|c|c|c|}
\hline \multirow[t]{2}{*}{ STATION } & \multicolumn{2}{|c|}{$\begin{array}{l}\text { COMPUTED AND MODEL GRAVITY } \\
\text { ANOMALY DIFFERENCE (mGal) }\end{array}$} & \multirow[t]{2}{*}{$\mathrm{A}^{2}$} & \multirow[t]{2}{*}{$\mathrm{B}^{2}$} \\
\hline & FREE AIR (A) & BOUGUER (B) & & \\
\hline RR01 & 0.16912 & 0.10544 & 0.028601430 & 0.011118558 \\
\hline AR02 & 8.72075 & 5.43749 & 76.051422786 & 29.566283226 \\
\hline AR04 & 0.09730 & 0.06067 & 0.009467704 & 0.003681229 \\
\hline UU08 & 0.43494 & 0.27119 & 0.189168682 & 0.073544158 \\
\hline XSU100 & 0.02087 & 0.01302 & 0.000435669 & 0.000169512 \\
\hline SR06 & 0.00076 & 0.00048 & 0.000000583 & 0.000000227 \\
\hline SK03 & -0.30792 & -0.19199 & 0.094813842 & 0.036860377 \\
\hline UU06 & 0.30428 & 0.18972 & 0.092587916 & 0.035995433 \\
\hline XSU92 & -0.24265 & -0.15129 & 0.058876702 & 0.022889941 \\
\hline UU04 & -0.06481 & -0.04040 & 0.004199750 & 0.001632441 \\
\hline UU01 & -0.00618 & -0.00385 & 0.000038157 & 0.000014839 \\
\hline AK03 & 0.14182 & 0.08843 & 0.020113573 & 0.007820100 \\
\hline AK05 & 0.00178 & 0.00111 & 0.000003174 & 0.000001229 \\
\hline AD03 & 0.00973 & 0.00606 & 0.000094732 & 0.000036773 \\
\hline MR03 & 0.04358 & 0.02718 & 0.001899588 & 0.000738604 \\
\hline EKS & -0.25472 & -0.15883 & 0.064884492 & 0.025225808 \\
\hline SLK01 & -3.31756 & -2.06854 & 11.006182692 & 4.278856636 \\
\hline SLK03 & -0.00539 & -0.00336 & 0.000029006 & 0.000011287 \\
\hline SLK05 & -0.00145 & -0.00090 & 0.000002098 & 0.000000814 \\
\hline EK02 & -0.09774 & -0.06094 & 0.009553030 & 0.003714245 \\
\hline EK05 & -0.00156 & -0.00097 & 0.000002422 & 0.000000946 \\
\hline \multirow[t]{3}{*}{ AIRPORT } & -5.64498 & -3.51972 & 31.865790402 & 12.388395235 \\
\hline & \multirow{2}{*}{\multicolumn{2}{|c|}{$\begin{array}{r}\text { RMSE }(\mathrm{mGal})= \\
\text { STANDARD ERROR }(\mathrm{mGal})=\end{array}$}} & 2.331 & 1.453 \\
\hline & & & 2.385 & 1.487 \\
\hline
\end{tabular}

\section{CONCLUSIONS AND RECOMMENDATIONS}

Having considered the application of gravity data in various fields such as geodesy, geology, geophysics, engineering among others, the study has modelled the free air and Bouguer gravity anomalies of Benin City and made the following conclusions and recommendations. 
1. The study has determined the gravity data of 22 points in Benin City from observed gravity measurements.

2. The obtained gravity data are termed local gravity anomalies as the theoretical gravity of the points were computed on the local ellipsoid (Clarke 1880 ellipsoid) adopted for geodetic computation in Nigeria.

3. It has also developed Microsoft Excel programs for the application of the models (free air and Bouguer gravity anomalies models) in the study area.

4. The computed Root Mean Square Errors (RMSEs) and the standard errors of the two models show high dependability, as well as the reliability of the models.

5. The study has recommended that whenever either free air or Bouguer gravity anomalies of points within Benin City are to be obtained for application in the field of geodesy, geology, geophysics and engineering, the determined models should be applied.

6. The study also recommends that in the application of the models in the study area, the local geographic coordinates of points of interest should be used.

\section{REFERENCES}

[1] Borga, M. and Vizzaccaro, A. (1996). On the Interpolation of Hydrologic Variables: Formal Equivalence of Multiquadratic Surface Fitting and Kriging. J Hydrol, Vol. 195, pp 160-171. In Ozturk, D. and Kilic, F. (2016). Geostatistical Approach for Spatial Interpolation of Meteorological Data. Anais da Academia Brasileira de Ciências, Vol. 88, No. 4, pp 21212136.

[2] Cattin, R., Mazzotti, S. and Laura-May Baratin, L. (2015). GravProcess: An Easy-to-Use MATLAB Software to Process Campaign Gravity Data and Evaluate the Associated
Uncertainties. Computers and Geosciences Vol. 81, pp 20-27. DOI: 10.1016/j.cageo.2015.04.005.

[3] Dawod, D. M. (1998). A National Gravity Standardization Network for Egypt. Published Ph.D Dissertation of the Department of Surveying Engineering, Shoubra Faculty of Engineering, Zagazig University. https://www.academia.edu/794554/The_egyptia n_national_gravity_standardization_network_E NGSN97_. Accessed 20th September, 2019.

[4] Dumitru, P. D., Plopeanu, M. and Badea, D (2013). Comparative Study Regarding the Methods of Interpolation. Recent Advances in Geodesy and Geomatics Engineering, pp 45-52. https://pdfs.semanticscholar.org/613c/25d7de55 dff3d099706f6b7c9f11acf77ad5.pdf. Accessed 25 September, 2019.

[5] Eteje S. O., Oduyebo O. F. and Ono M. N. (2019). Derivation of Theoretical Gravity Model on the Clarke 1880 Ellipsoid for Practical Local Geoid Model Determination. Scientific Research Journal (SCIRJ), Vol. 7 No. 2, pp 1219. DOI: 10.31364/SCIRJ/v7.i2.2019.P0219612.

[6] Eteje, S. O. and Oduyebo, F. O. (2018). Local Geometric Geoid Models Parameters and Accuracy Determination Using Least Squares Technique. International Journal of Innovative Research and Development (IJIRD), Vol. 7, No 7, $\quad$ pp 251-257. DOI: 10.24940/ijird/2018/v7/i7/JUL18098.

[7] Eteje, S. O., Oduyebo, O. F. and Oluyori, P. D. (2019). Relationship between Polynomial Geometric Surfaces Terms and Observation Points Numbers and Effect in the Accuracy of Geometric Geoid Models. International Journal of Environment, Agriculture and Biotechnology (IJEAB), Vol. 4, No. 4, pp 1181-1194. DOI: 10.22161/ijeab.4444.

[8] Ismail, N. H. (2015). Gravity and Magnetic Data Reduction Software (GraMag2DCon) for Sites Characterization. Published Ph.D Dissertation 
of the Universiti Sains Malaysia. http://eprints.usm.my/31969/1/NOER_EL_HID AYAH_ISMAIL.pdf. Accessed 25 September, 2019.

[9] Jassim, F. A. and Altaany, F. H. (2013). Image Interpolation Using Kriging Technique for Spatial Data. Canadian Journal on Image Processing and Computer Vision, Vol. 4, No. 2, pp 16-21.

[10] Kaye, J. (2012). The Interpolation of Gravitational Waveforms. Published Thesis of the Division of Applied Mathematics, Brown University.

https://www.brown.edu/research/projects/scien tific-

computing/sites/brown.edu.research.projects.sci entific-

computing/files/uploads/The\%20interpolation.p df. Accessed 25 September, 2019.

[11] Lederer, M. (2009). Accuracy of the Relative Gravity Measurement. Acta Geodyn. Geomater., Vol. 6, No. 3, pp 383-390.

[12] Märdla, S., Ågren, J., Strykowski, G., Oja, T., Ellmann, A., Forsberg, R., Bilker-Koivula, M., Omang, O., Paršelinas, E. and Liepinš, I. (2017). From Discrete Gravity Survey Data to a Highresolution Gravity Field Representation in the Nordic-Baltic Region. Marine Geodesy, Vol. 40, No. 6, pp 416-453. DOI: 10.1080/01490419.2017.1326428.

[13] Mariita, N. O. (2009). The Gravity Method. Proceedings of Short Course IV on Exploration for Geothermal Resources, organized by UNUGTP, KenGen and GDC, at Lake Naivasha, Kenya.

[14] Mathews, L. R., and McLean, M. A. (2015). Gippsland Basin Gravity Survey. Geological Survey of Victoria Technical Record. https://earthresources.vic.gov.au/_data/assets/p df_file/0011/456743/G6-Gippsland-gravity-
survey-report-June-2015.pdf. Accessed 20th September, 2019.

[15] Mickus, K. (2004). Gravity Method: Environmental and Engineering Applications. http://citeseerx.ist.psu.edu/viewdoc/download?d $\mathrm{oi}=10.1 \cdot 1.522 .2552 \&$ rep=rep1\&type=pdf.

Accessed 20th September, 2019

[16] Murray, A. S. and Tracey, R. M. (2001). Best Practice in Gravity Surveying. Australian Geological Survey Organization. https://d28rz98at9flks.cloudfront.net/37202/372 02.pdf. Accessed 20th September, 2019.

[17] Nasuti, A., Beiki, M. and Ebbing, J. (2010). Gravity and magnetic data acquisition over a segment of the Møre-Trøndelag Fault Complex. Geological Survey of Norway NO-7491 Trondheim, Norway.

[18] Oluyori, P. D. and Eteje, S. O. (2019). Spatial Distribution of Survey Controls and Effect on Accuracy of Geometric Geoid Models (Multiquadratic and Bicubic) in FCT, Abuja. Scientific Research Journal (SCIRJ), Vol. 7, No. 5, pp 2935. DOI: 10.31364/SCIRJ/v7.i5.2019.P0519650.

[19] Ono, M. N., Eteje, S. O. and Oduyebo, F. O. (2018). Comparative Analysis of DGPS and Total Station Accuracies for Static Deformation Monitoring of Engineering Structures. IOSR Journal of Environmental Science, Toxicology and Food Technology (IOSR-JESTFT), Vol. 12, No. 6, PP 19-29. DOI: 10.9790/24021206011929.

[20] Ozturk, D. and Kilic, F. (2016). Geostatistical Approach for Spatial Interpolation of Meteorological Data. Anais da Academia Brasileira de Ciências, Vol. 88, No. 4, pp 21212136.

[21] Saibi, H. (2018). Microgravity and Its Applications in Geosciences. GravityGeoscience Applications, Industrial Technology and Quantum Aspect. DOI: 10.5772/intechopen.71223. 
https://cdn.intechopen.com/pdfs/57238.pdf.

Accessed 20th September, 2019.

[22] SpongIer, D. P. and Libby, F. J. (1968). Application of the Gravity Survey Method to Watershed Hydrology. Issue of Ground Water, Vol. 6, No. 6.

[23] Valenta, J. (2015). Introduction to Geophysics Lecture Notes. Czech Republic Development Cooperation.

http://www.geology.cz/projekt681900/english/1 earning-

resources/Geophysics_lecture_notes.pdf

[24] Van-Beers, W. C. M. and Kleijnen, J. P. C. (2003). Kriging for Interpolation in Random Simulation. Journal of the Operational Research Society, Vol. 54, pp. 255-262. In Jassim, F. A. and Altaany, F. H. (2013). Image Interpolation Using Kriging Technique for Spatial Data. Canadian Journal on Image Processing and Computer Vision, Vol. 4, No. 2, pp 16-21.
[25] Yilmaz, M. and Kozlu, B. (2018). The Comparison of Gravity Anomalies based on Recent High-Degree Global Models. Afyon Kocatepe University Journal of Science and Engineering, Vol. 18, pp 981-990.

Cite this article as : Eteje, S. O., Oduyebo O. F., Oluyori P. D., "Modelling Local Gravity Anomalies from Processed Observed Gravity Measurements for Geodetic Applications", International Journal of Scientific Research in Science and Technology (IJSRST), Online ISSN : 2395-602X, Print ISSN : 23956011, Volume 6 Issue 5, pp. 144-162, SeptemberOctober 2019. Available at doi : https://doi.org/10.32628/IJSRST196515 Journal URL : http://ijsrst.com/IJSRST196515 